\title{
Stem Cell Research and Social Justice: Aligning Scientific Progress with Social Need
}

\author{
Brooke Ellison ${ }^{1}$
}

Published online: 8 October 2016

(C) Springer International Publishing AG 2016

\begin{abstract}
As stem cell research moves toward clinical translation and therapeutic application, ethical focus must be broadened to include questions about the interface of science and society. Among these societal questions is how to conduct this research in a socially just manner, as well as how and why stem cell research ought to be used as a vehicle to advance social justice imperatives. This article provides an overview of justice as a social and philosophical construct, and how it can be incorporated into science discussions. This review then addresses prominent social justice challenges, especially as they relate to biomedical research and healthcare, and how stem cell research might be a mechanism to reduce the burden of these injustices. Finally, this article concludes with ways to structure our ethical thinking and scientific debate in order to determine if stem cell research is being pursued in a socially just manner.
\end{abstract}

Keywords Stem cell research $\cdot$ Ethics $\cdot$ Justice $\cdot$ Health disparities · Global health $\cdot$ Community engagement

\section{Introduction}

As a scientific community and society, we are nearing viable stem cell-based therapies and applications. The translation from basic science to therapies, however, raises ethical

This article is part of the Topical Collection on Ethics in Stem/Progenitor Cell Therapeutics

Brooke Ellison

brooke.ellison@stonybrook.edu

1 School of Health Technology and Management, Stony Brook University Stem Cell Facility, Stony Brook, NY 11794, USA questions that require thoughtful deliberation about how research is prioritized and to whom scientific advances are made available. This analysis will address justice-based questions that are raised by the translation of stem cell science to therapeutics, as well as by how the science, itself, is conducted. For the purposes of this review, "stem cell research" will include applications that involve adult, human embryonic, and induced pluripotent stem cells. The intersection of justice and stem cell research provides fertile ground for the examination of how the benefits of science are most broadly enjoyed, whose interests are most immediately addressed, and how science can be a mechanism to reduce social disparities. This examination will help to create science that is socially just.

\section{Stem Cell Research}

Many of the ethical questions surrounding stem cell research and regenerative medicine have focused on aspects of the science, itself. Rigorous debates have generated meaningful public dialog and, despite ongoing differences of opinion, have provided a regulatory framework within which important science has been conducted. We are in a different age now, and the practical ethical questions surrounding stem cell research are much broader and socially relevant. How to conduct the translation of stem cell research and regenerative medicine to therapeutics in a socially just manner is central among these questions. What social justice claims can be made on stem cell science, how can it be practiced more justly, and how can it help to address social injustices? These questions will be central in creating a social justice context and mandate for the future of this work. First, let us define some of the concepts implicit in these questions. 
Social justice, or justice more generally, has long been the subject of philosophical debate, and theorists and social thinkers have differed on what this concept means. Justice has especially been debated in the context of how to distribute resources and benefits across members of a society, and within this framework, there are several forerunning perspectives. Some thinkers, like John Stuart Mill and others, have argued for a utilitarian approach to justice. Under this understanding of justice, justice coincides with the promotion social welfare and structuring distribution to best achieve this outcome [1]. Others, like Robert Nozick, have proposed a libertarian understanding of justice, in which justice is predicated on the principles of just acquisition and just transfer. A libertarian approach to justice argues that free market principles and actions are inherently just and attempts at redistribution without consent are fundamentally unjust and in violation of property rights [2]. These two approaches to justice leave much to chance and do not sufficiently account for disparities in access to resources, power, or influence, which are often present in society. Another approach, offered by John Rawls, is an understanding of justice based on fairness, which incorporates how we ought to distribute goods and services when there is a differential in access to power and social structure [3]. Overcoming social disparities and barriers becomes a collective necessity when society can no longer operate properly because of them.

In his work, A theory of justice, philosopher John Rawls takes a Kantian approach to justice, in which all people are able by virtue of being people, and ought not to be subject to arbitrary disadvantage brought about by a "natural lottery." To this end, Rawls argues in his "difference principle" that social inequalities and the distribution of goods and services ought to be to the benefit of the least advantaged [3]. Rawls was, by no means, alone in this understanding of justice, and its implications are significant. As Harvard professor, Marshall Ganz, has stated, "inequality, it's not just about wealth, it's about power. It isn't just that somebody has yachts, it's the effect on democracy" [4]. Those in positions of poverty, exacerbated by racism and ableism, also have worse health, fewer educational opportunities, lower-paying jobs, and substandard housing [4]. A commitment to justice implies concern for reducing the burden of inequality, both directly and indirectly.

As studies have indicated, within the context of the USA, the least well-off are often members of racial, ethnic, and ability minorities who, by virtue of social, political, and health disparities, are disproportionately denied access to adequate income, dignity, health, or respect. However, these individuals often are also left out of social conversations and the scientific research process, especially the biomedical research apparatus, creating a bifurcated degree of social injustice: one in which they experience disparities and one in which they are marginalized from the mechanisms by which disparities can be reduced. Addressing these disparities is an unprecedented opportunity - if not, a mandate - for science, as science has the capacity to broaden the social divide that perpetuates disparity and injustice, or it has the capacity to reduce it. Stem cell science is no exception.

\section{Stem Cell Research as a Vehicle for Social Justice}

Stem cell research will be among the most prolific areas of scientific inquiry in the coming decades. The pursuit of science must not only be to drive knowledge economies, which recognize knowledge as a driver of productivity and economic growth [5], but also to improve the state of the world. Biomedical and health-related research can be a vehicle for health equity and, as a result, social justice. However, there are practices and policies within the stem cell research framework that have hampered its most just progression.

Some have questioned the ethics of stem cell and biomedical research from a justice-based standpoint, arguing that money spent on expensive and complex science could more justly be spent on public health treatments for the world's poorest. This argument is, by no means, illegitimate or unfounded. For instance, the Bill and Melinda Gates Foundation has committed $\$ 10$ billion to the development of vaccines to be scaled up and delivered to an estimated 8 million children in developing countries by year 2020 . The immensity of this initiative is clear and its impact is overwhelming. As the Gates Foundation stated, through access to DTP3 vaccine in the poorest countries, the number of people who died of conditions like measles fell by $77 \%$ between 2000 and 2008 [6]. In Africa alone, measles death fell by $92 \%$. Yet, the need for increased investment in vaccine-related activities, such as basic research and innovations in delivery, remains high, especially to treat conditions like diarrhea and pneumonia, which are among the leading causes of childhood death internationally. One could argue that funds directed toward stem cell research could easily be used to develop and deliver vaccines to children around the world. From a utilitarian point of view, investing precious resources into research in which many people could be benefited at one time would be a just approach. From a Rawlsian justice perspective, one could, and some have, made a similar argument that precious dollars ought to benefit diseases and conditions most characteristic of underserved societies.

While initially enticing, this argument is incomplete and, in some ways, irrelevant. Under this approach, we, the beneficiaries of science, are implicitly being asked to evaluate the relative worthiness of two, equally important, avenues of scientific exploration. In essence, it is asking us to choose one avenue of scientific exploration over another, when both have significant potential to create a stronger future. A better, and certainly more just, approach would be to look at how all science is practiced and applied and determine what strategies 
can be employed to broaden its benefits and include those who have historically been marginalized from science.

\section{Reducing Health Disparities}

One of the most immediate manifestations of social injustice is health disparities. The idea that members of different racial, ethnic, ability, and socioeconomic groups experience disparities in health is neither new nor, in and of itself, especially insightful. New insights can most significantly be derived when it comes to strategies to address these disparities in a multifaceted manner. While many initiatives will and must address the societal and institutionalized structures that give rise to social inequality, others must focus on the disparate burden of disease and disability found in marginalized groups. This is an act of social justice.

Individuals in resource-poor communities experience stressors on mind and body due to environmental exposures, which present themselves in disparate risk of illness and disease [7]). Notable disparities include those in areas such as asthma, cancer, liver disease, diabetes, heart disease, hepatitis, HIV/AIDS, and mental health. For instance, Black and African American US citizens experience asthma at an 8.6 prevalence percentage, as opposed to 7.3 in their White counterparts [8]. In 2012, African Americans were 20 times more likely to be diagnosed with asthma. Similarly, African Americans are about 1.5 times more likely than Whites to be diagnosed with lung or prostate cancer. In addition, African Americans are $70 \%$ more likely to develop chronic liver disease. According to the US Department of Health and Human Services, the risk of diabetes is much greater for members of racial minority populations than for their White counterparts [9]. Specifically, the prevalence of diabetes among African Americans is 10.8 versus $6.2 \%$ among Whites [10]. These data produce an overall picture of health that is much bleaker for Blacks than for Whites, such that the life expectancy of Whites is 78.3 years, while it is 73.1 years for Blacks [11].

Science, like society, has an opportunity to address these injustices, but it requires comprehensive work to do it. Addressing health disparities through advances in stem cell science will require focusing on these health issues, in particular, as well as developing strategies to broaden a public involvement in science. Fortunately, there is no shortage of stem cell research dedicated to the health conditions that disproportionately affect racial and ethnic minorities in the USA, conditions like asthma, heart disease, liver disease, and HIV/ AIDS. For example, mesenchymal stem cells have been explored extensively as a potential treatment for asthma [12-14]. In addition, a plethora of research has been conducted on the use of stem cells to understand and treat cardiac damage following heart disease [15-17]. In fact, there are few diseases and disorders that are not being investigated for their applicability to stem cell-based treatment. The question lies much more centrally on how to bring marginalized people into the research folds and how to ensure that advances made in the stem cell field are accessible to everyone. There are both logistical and strategic ways to do this.

\section{Diversifying Genetics of Stem Cell Lines}

The cornerstone of the Bush administration's restrictions on embryonic stem cell research was its exclusivity to providing federal funding to research on stem cell lines already in existence prior to the August 9, 2001, policy date. This restriction was troublesome for stem cell scientists for many reasons but among these was the fact that the allegedly 60 embryonic stem cell lines (though realistically far fewer) were explicitly from supernumerary IVF embryos donated to research, stipulating that these embryos were to have been created for reproductive not research purposes. As noted by organizations like the American Association for the Advancement of Science (AAAS), alarm was immediately raised across the scientific community that, given the largely White and upper-middleclass demographic which characterizes IVF couples, these existing cell lines would lack genetic variability. As the AAAS stated, "genetic diversity of the available cell lines is an important consideration in determining the value of your research" [18].

The concerns raised by scientists immediately following the issued stem cell funding restrictions were supported by analyses done shortly thereafter, when an investigation highlighted the problematic nature of genetic nondiversity [19], among existing stem cell lines. The researchers concluded that the allelic frequencies that differ for many single nucleotide polymorphisms across ethnicities were not present in many of the existing stem cell lines. In addition, the authors concluded that introducing stem cell lines from donors of diverse ethnicities would also ensure diversity in genetic backgrounds of these cell lines and, more importantly, the generalizability of results of the research conducted on them.

In 2007, the advent of induced pluripotent stem cells (iPSCs), through which stem cell lines of a chosen genotype could be developed, offered a means to address the relative lack of genetic diversity in existing stem cell lines. This breakthrough essentially meant that researchers could have access to a nearly unlimited resource for cell therapy [20]. What is more, scientists have developed iPSC lines with specific genetic characteristics and even the possibility of autologous patient-specific stem cell lines, though the practicality and logistical feasibility of this application for everyone in need may prove to be too daunting. However, another possibility is the creation of banks of iPSC lines from cells donated by donors chosen specifically to reduce the likelihood of immune cell response. This idea has been proposed, in which iPSCs have been created using the concept known as "hemi-similarity," through which donors are matched to potential recipients 
based on matching only a handful of human leukocyte antigen (HLA) genes. Through this process, it is feasible to create a stem cell bank, or "haplobank," which could serve the needs of nearly everyone through the creation of only a few thousand cell lines.

This is a groundbreaking effort and one in which organizations like the New York Stem Cell Foundation, in its Global Stem Cell Array, and the UK's Human iPSC Initiative (HipSci) have already begun. However, in order to do this comprehensively, it will require a significant outreach and engagement initiative, similar to that undertaken by President Obama's Precision Medicine Initiative [21]. This is where the future of science and the importance of community engagement intersect.

\section{Community Engagement and Participatory Research}

Just as we can conduct science research that is socially just, we can conduct science practice and application that is, likewise, socially just. This is essential for broadening the public base for science, as well as growing the population that might contribute to it. How research relates to the public is generating attention as its practical advances become more intimately intertwined with people's lives. The impetus behind movements to democratize scientific practice is bidirectional: stemming from the public grassroot advocacy and special interest groups that call for greater participation in science and stemming from scientists, themselves, who benefit from more extensive public awareness of scientific aims. As informal, and sometimes even nonexistent, as it has been over the years, the relationship between science and community engagement is a mutually reinforcing one, from which everyone gains. As Peter Little has argued, "we . . . need to develop more responsible critiques of . . . the democratization of science if we wish to better understand the role of science in citizen struggles." [22]. The democratization of science is also a mechanism of social justice.

What is the purpose of community engagement in science, and what is the normative justification for caring about it? For many domains of science, particularly those that have immediate relevance to human lives, scientific ends are inextricably connected to people. When the impersonal nature of science is not influenced by the thoughts and concerns of the community within which it operates, it loses its most critical social characteristic. While maintaining proper oversight and adhering to the highest ethical standards, a better balance can be struck between scientific autonomy and the values or objectives of community members who feel the effects of scientific advances: one that communicates scientific objectives and progress more concisely and one that hears a community voice more clearly. The relationship between science and the public is a mutually reinforcing one, but it is underappreciated and quite fragile. This is particularly the case for members of racial and ethnic minorities who have often been left out of the research process at all levels. While this argument has always been true, now, the advances of science like stem cell research have become more complex, more intertwined, and more deeply incorporated into all aspects of epistemic and social life.

Community engagement in science involves bringing members of the public, particularly marginalized communities, into research and bringing research to the public. However, science is a discipline that is unaccustomed to soliciting input and has historically viewed "the public" as objects of, not partners in, research. Incorporating democratic ideals into research helps to indicate what members of the public want from science, where their anxieties lie, and how to shrink the gap between what is conducted in the laboratory and what is experienced in the community. For stem cell research, where the projected course of the research is still being plotted and what it can and cannot achieve is still being determined, community engagement and public involvement may prove invaluable as the field progresses from basic research to potential therapies. "Community engagement" and "public involvement" have gained traction across many domains of academia, most notably public health and behavioral sciences. While community-based research and community engagement might seem evident and, in fact, necessary in behavioral and social sciences, what might this look like in basic science?

Community engagement in the sciences is undeniably beneficial, especially in areas of science that deal with matters of social injustice. Health disparities have been investigated from the research orientation known as community-based participatory research (CBPR), which is a perspective on social science research that "prioritizes developing capacity, improving trust, and translat[ing] knowledge to action" [23•]. CBPR involves the equitable involvement of community members in the research process, putting researchers and the community in a co-learning environment that builds capacity and community strengths and promotes action. CBPR is known to improve research quality, increase the dissemination of information among marginalized groups, assist in the implementation of scientific or health-related interventions, and enhance the community/academic relationship. CBPR represents perhaps the most comprehensive engagement methodology, yet others have also have been effective at involving the public in science. For instance, social media interaction, community forums and panel discussions, and nonacademic writing have been explored to reduce the divide between science and society, to bring science to the community, and to bring the community into science. More of these efforts ought to be attempted to determine effectiveness and to provide mechanisms for interactive learning.

As argued by many in the science field, including the Centers for Disease Control and Prevention (CDC), the value of community engagement in science is multifaceted, 
allowing researchers to reconstruct the objectives and moral foundations of their work so that they are in alignment with those who might benefit from scientific advancement and those who will be involved in the clinical trial process. Increasing racial, ethnic, and other minority representation in clinical trials is an imperative, as the composition of clinical trial participants has been dominated by Caucasian Americans. For instance, while African Americans make up $12 \%$ of the US population, they comprise only $5 \%$ of clinical trial participation [24]. Similarly, Hispanics make up $16 \%$ of the population but only $1 \%$ of clinical trial participants [24]. What is more, a recent study [25] has indicated that even within racial groups like Blacks in the USA, there is important genetic diversity found across geographical divides that ought to be taken into account in order for scientific advances to be practical and useful for everyone. This is significant because diversity in clinical trial design is essential to deriving meaningful public health information and for understanding how genetic differences might produce different responses to drugs and pharmaceuticals. However, overcoming this disparity in representation has been difficult, as there have been historical circumstances in which members of ethnic, racial, and gender minorities were mistreated. These have left a lasting negative perception of research among members of minorities, as a disproportionately high number of racial and ethnic minorities do not have confidence in the research process. This can best be overcome through community engagement.

\section{Stem Cell Research and Global Health}

A Rawlsian perspective of justice is built on a contractarian framework that only applies within nations and among members of common societies. Yet, global inequality and global justice also ought to be of concern to policymakers and justice seekers. To this end, a more globally oriented theory of justice, the capability approach, was introduced by philosophers, Amartya Sen and Martha Nussbaum. The capability approach argues that individual and social well-being is judged in terms of people's capability to perform the functions required for a full and meaningful life. As Sen has argued, in comparing the well-being of people in different societies, there is a distinction in their capacity to convert income and commodities into valuable achievements. As a result, it is important to look at the resources required for people of different capabilities to achieve the same outcome [26].

The evolution of global inequality is long and arises from sociocultural complexities that our collective conscience is only beginning to comprehend. Political economists have looked at power imbalances between the global North and global South largely through a lens of economic injustice. However, other analyses have taken a more expansive approach and have positioned global inequality within a network of racial, political, and cultural domination that has been interwoven with economic principles to create a significant disparity over access to resources important for a life capability [27••]. In 2005, London made the critical claim that "justice is properly about the basic social structures ... (political, legal, social, and economic institutions of the community that have a profound impact on the health status of community members) and whether these structures guarantee community members the "fair value' of their most basic human capacities" [28*0]. Disparities in health across nations, brought about by equal access to resources, indicate that this vision justice is not being met sufficiently.

Health-related disparities between the resource-rich global North and the resource-poor global South are significant in number and depth; however, the most pressing health challenges involve communicable diseases. Communicable diseases are diseases that spread from a host, like a person or animal, to another person via virus or bacteria [29]. Among the most prevalent and deadly communicable diseases that cause the greatest global health threats are hepatitis, HIV/ AIDS, influenza, malaria, polio, and tuberculosis. For instance, according to the President's Malaria Initiative, malaria is a preventable parasitic disease transmitted by mosquitoes and, in 2013, infected some 198 million people worldwide [30]. This disease is especially prevalent in sub-Saharan Africa, where $90 \%$ of all malaria deaths occur. There are important ways that advances in stem cell research and emerging biomedical technologies intersect with these global health challenges.

As the Centers for Disease Control presented, malaria is inextricably linked with poverty, as the highest malaria mortality rates are seen in countries with the highest rates of extreme poverty (proportion of population living on less than $\$ 1.25$ per day) [31]. Strategies to reduce the burden of this disease have largely and, effectively, focused on disease prevention. However, advances and work done in stem cell research have offered new understandings for ways to treat deadly communicable diseases. For instance, in 2015, a study indicated the promise of bone-marrow-derived mesenchymal stromal cells (BM-MSCs) to treat cerebral malaria, a severe form of malaria and leading cause of malaria mortality. The researchers found that transplantation of BM-MSCs increased survival, reduced parasitemia, decreased malaria treatments and simulation in the spleen, liver, and kidney, elevated Kupffer cell count, alleviated renal injury and lung inflammation, and improved lung mechanics in a mouse model [32].

Another communicable disease that disproportionately affects developing nations is the hepatitis B virus (HBV), which infects some 400 million people worldwide. Research and treatment for this condition have been limited to in vitro cell culture systems that support the infection of human hepatocytes. Human hepatocytes produce innate immune responses associated with certain genes [33]. This has been studied using micropatterned co-cultures of hepatocytes with blocked 
genes. However, hepatocytes differ from individual to individual in their susceptibility to HBV infection, which suggests that certain genetic factors may influence acquiring the infection. In order to investigate genetic differences, researchers have developed iPSC lines, differentiated into hepatocytelike cells. The use of stem cell-derived cell systems has allowed for new understandings of the genetics and physiology of this condition.

Finally, extensive work has been done to pursue the possibility of using stem cell therapy, particularly bone marrow gene therapy that uses hematopoietic stem cells, to treat HIV/AIDS [34]. The HIV epidemic currently affects 35 million people worldwide, having killed some 25 million people since it was first identified in 1981. While combination antiretroviral therapy has been shown to prolong the lives of HIVinfected individuals, 30 years of research have failed to produce an effective and durable HIV vaccine. In addition, studies have suggested that "the toxicity associated with the lifelong adherence to [combination antiretrovirals therapy], together with all the appearance of drug-resistant HIV variants in some patients, supports the continuous search for novel and original ways to fight HIV." Additional studies using stem cells and genomic editing have offered insights into new avenues for treatment of HIV/AIDS. For instance, Li and colleagues [35] have demonstrated effective treatment of HIV through an allogeneic stem cell transplant focusing on the HIV-1 coreceptor CCR5, which is a validated target for HIV/AIDS therapy. The researchers transplanted hematopoietic stem cells homozygous for a naturally occurring CCR5 deletion mutation that appeared to eliminate HIV-1 in test subjects. The researchers suggest that, as naturally occurring CCR5 deletion mutation is very rare, genetic engineering of autologous hematopoietic stem/progenitor cells could be an effective HIV/AIDS therapy.

The need for application of stem cell research to the understanding and treatment of communicable diseases that target developing countries remains immediate and relevant. The recent Zika virus threat demonstrates precisely how true this is. Between 2015 and 2016, the Zika virus became a significant public health threat throughout South America and the USA. Transmitted by mosquitoes, the Zika virus can result in microcephaly in babies of infected pregnant mothers, with babies dying shortly after they are born. What is just as troubling is that many of the particulars of this disease are not understood. However, as ethicist Jonathan Moreno has argued, understanding the mechanism by which the virus affects neural stem cells and, thus, neurological development could open a pathway to preventing the microcephalic condition in infants [36].

\section{Stem Cell Research and Economic Justice}

These studies suggest that, while stem cell therapy is often aimed at understanding congenital disorders and disability, there is a new trajectory of this research that has application for global health challenges like communicable diseases. However, in order for stem cell therapies to be a practical option to treat these deadly diseases, they must be affordable and accessible to those who need them. The question of distributive justice and access to stem cell-related therapies has been a complex one among ethicists in the field. The social justice questions arise when the cost of treatment becomes so high that patients in need are priced out of the care that others can get. In a study aimed at identifying the factors that affect whether patients received stem cell transplantation, researchers found that receiving a hematopoietic stem cell transplant had a significant impact on mortality but that getting this transplantation was highly affected by access to private insurance and residence in a well-educated county [37]. This finding presents a disparity between those who have access to treatment and those who do not: those who will live and those who likely will not.

Efforts have been made to estimate a cost structure or model for a hematopoietic stem cell transplantation program [38]. Researchers looked at strategies for performing hematologic transplantation at a public institution dedicated to uninsured patients. The model was designed to be cost efficient and maximize scarce financial resources. Using individualized costs for standard drugs and therapeutics, as well as laboratory and procedural costs, the model developed by these researchers had an estimated cost of $\$ 12,500$ for an allogeneic hematopoietic stem cell transplant. While this finding is applicable to the treatment of congenital disorders, similar models must be adopted for the future treatment of communicable diseases, especially in developing nations that will feel the effects of these conditions most strongly.

As concern over the affordability of potential stem cell treatments has gained traction, some have discussed the importance of such things as public cord blood banks to take the place of private cord blood banks [39]. As these researchers argue, public cord blood banks are publicly owned and funded banks that collect umbilical cord blood from any willing donor for the use of any public recipient for whom the stem cells are a match. This strategy provides the potential for stem cell treatment for those who might not have had the resources to privately store cord blood cells.

Nevertheless, the question of how to justly provide the benefits of stem cell advances remains an unsettled one and will require ongoing deliberation. It remains a moral imperative to ensure that stem cell advances do not create a hierarchy or discriminatory practices based on wealth, geography, or race. As the research advances and as we become more deeply immersed in the therapies that arise through stem cell science, these conversations must continue, and innovative solutions must be pursued so that science can remain a public good. 


\section{Conclusion}

Stem cell science is pursuing areas of disease research that will benefit all, especially those in positions of social disadvantage at both national and international levels. Questions remain, however, to what degree the processes of the science can be conducted in more just manner. Such processes so central to stem cell science include such things as applicability of scientific breakthroughs to everyone, the construct of clinical trials, and the cost of the delivery of treatments that might emerge from the research. Stem cell science must begin to democratize its practice through the incorporation of community voices and the vantage points of community members of diverse backgrounds, and it would behoove scientists to learn what is of value marginalized communities and then engage in conversations to bring these community members into the research. It is only through these strategies that scientists can learn from community members, and it is only through these strategies that we can develop clinical trials that are diverse, stem cell lines that are likewise diverse, and a trust in science that has eluded the discipline for too long. In addition, we must begin to discuss meaningfully how the advances of stem cell science will be made affordable and obtainable to people from all economic backgrounds and regions of the world. Few steps have been taken to this end, and many more remain, but this will be critical in establishing a social justice ethic for this science.

\section{Compliance with Ethical Standards}

Conflict of Interest Brooke Ellison declares that she has no conflict of interest.

Human and Animal Rights and Informed Consent This article does not contain any studies with human or animal subjects performed by any of the authors.

\section{References}

Papers of particular interest, published recently, have been highlighted as:

- Of importance

•. Of major importance

1. Mill John Stuart. Utilitarianism. Chapter 5: on the connection between justice and utility. 1863.

2. Nozick R. Anarchy, state, and utopia. Wiley-Blackwell; New Ed edition; 1974.

3. Rawls J. Theory of justice. Cambridge: Harvard University Press; 1971.

4. Powell A. When a fair shake isn't: the cost of inequality in America. Cambridge: Harvard University Gazette; 2016.

5. World Health Organization. The WHO strategy for research for health. Geneva, Switzerland: WHO Press; 2012.
6. Bill \& Melinda Gates Foundation. Bill and Melinda Gates pledge $\$ 10$ billion in call for decade of vaccines | Bill \& Melinda Gates Foundation. 2010. Press Release retrieved online from: http://www. gatesfoundation.org/Media-Center/Press-Releases/2010/01/Billand-Melinda-Gates-Pledge-\$10-Billion-in-Call-for-Decade-ofVaccines.

7. Gómez LE, López N. Mapping "race" [electronic resource] critical approaches to health disparities research /edited by Laura E. Gómez and Nancy López. New Brunswick, NJ: Rutgers University Press, 2013.

8. U.S. Department of Health and Human Services, Office of Minority Health. 2016. Minority patient profiles. Retrieved online from: http://minorityhealth.hhs.gov/omh/browse. aspx?lvl=2\&lvlid=26.

9. Diabetes \& Disparity among Racial and Ethnic Minorities Fact Sheet. 2012.

10. Mokdad AH, Serdula MK, Dietz WH, Bowman BA, Marks JS, Kaplan JP. The continuing epidemic of obesity in the United States. JAMA. 2000;(13)

11. Williams DR, Sternthal M. Understanding racial-ethnic disparities in health: sociological contributions. J Health Soc Behav. 2010;51(Suppl):S15-27. doi:10.1177/0022146510383838.

12. Song X, Xie S, Lu K, Wang C. Mesenchymal stem cells alleviate experimental asthma by inducing polarization of alveolar macrophages. Inflammation. 2015;38(2):485-92.

13. Trzil JE, Masseau I, Webb TL, Chang C, Dodam JR, Cohn LA, Liu H, Quimby JM, Dow SW, Reinero CR. Long-term evaluation of mesenchymal stem cell therapy in a feline model of chronic allergic asthma. Clin Exp Allergy. 2014;12:1546. doi:10.1111/cea.12411.

14. Kuo Y, Li YJ, Zhou J, Shih YV, Miller M, Broide D, Lee Chien S. Human Mesenchymal stem cells suppress the stretch-induced inflammatory miR-155 and cytokines in bronchial epithelial cells. 2013.

15. Kim J, Shapiro L, Flynn A. The clinical application of mesenchymal stem cells and cardiac stem cells as a therapy for cardiovascular disease. Pharmacol Ther 2015;8. doi:10.1016/j.pharmthera.2015.02.003.

16. Khanabdali R, Rosdah AA, Dusting GJ, Lim SY. Research update: harnessing the secretome of cardiac stem cells as therapy for ischemic heart disease. Biochem Pharmacol. 2016. doi:10.1016/j. bcp.2016.02.012.

17. Lambert V, Gouadon E, Capderou A, Le Bret E, Ly M, Dinanian S, Renaud JP, Puceat M, Rücker-Martin C. Congenital heart disease: Fontan: right ventricular failure secondary to chronic overload in congenital heart diseases: benefits of cell therapy using human embryonic stem cell-derived cardiac progenitors. J Thoracic Cardiovasc Surg. 2015;149708-715.e1. doi:10.1016/j. jtcvs.2014.11.033.

18. Recer P. Scientists challenge Bush administration to identify 60 stem cell lines. Billings Gazette. 2001. http://billingsgazette. com/news/world/scientists-challenge-bush-administration-toidentify-stem-cell-lines/article cd7e880c-3a13-5e78-a2f9-48df09 f47128.html.

19. Laurent L, Nievergelt C, Lynch C, Fakunle E, Harness J, Schmidt U, Galat V, Laslett A, Otonkoski T, Keirstead H, Schork A, Park H, Loring J. Restricted ethnic diversity in human embryonic stem cell lines. Nat Methods. 2010;7(1):6-7.

20. Gourraud P, Gilson L, Girard M, Peschanski M. The role of human leukocyte antigen matching in the development of multiethnic "haplobank" of induced pluripotent stem cell lines. Stem Cells (Dayton, Ohio). 2012;30(2):180-6. doi:10.1002/stem.772.

21. Precision Medicine Initiative. Precision Medicine Initiative: about. 2016. Retrieved online from: https://www.nih.gov/precisionmedicine-initiative-cohort-program.

22. Little P. Negotiating community engagement and science in the federal environmental health sector. Med Anthropol Q. 2010;23(2):94-118. 
23. Frerichs L, Hassmiller LK, Dave G, Corbie-Smith G. Integrating systems science and community-based participatory research to achieve health equity. Am J Public Health. 2016;106(2):215-22. doi:10.2105/AJPH.2015.302944. This article discusses the importance and utilization of CBPR techniques to address health disparities.

24. Food \& Drug Administration, Clinical trials shed light on minority health. 2013. Retrieved online from: http://www.fda. gov/ForConsumers/ConsumerUpdates/ucm349063.htm.

25. Baharian S, Barakatt M, Gignoux CR, Shringarpure S, Errington J, Blot WJ, et al. The great migration and African-American genomic diversity. PLoS Genet. 2016;12(5):e1006059. doi:10.1371/journal. pgen.1006059.

26. Sen A. Human rights and capabilities. J Hum Dev. 2005;6(2):1-16.

27.• Bashi Treitler V, Boatcă M. Dynamics of inequalities in a global perspective: an introduction. Curr Sociol. 2016;64(2):159-71. doi:10.1177/0011392115614752. This article addresses the forms of political and racial oppression that have given rise to global inequality. This article makes the case for a socio-cultural perspective on inequality.

28.• Benatar SR. Global health and justice: re-examining our values. Bioethics. 2013;27(6):297-304. This article addresses the bioethical construct of justice and how it must be incorporated into our science and global health debates.

29. Wisconsin Department of Health Services. Communicable disease. 2016. Retrieved online from: https://www.dhs.wisconsin. gov/disease/index.htm.

30. President's Malaria Initiative. President's Malaria Initiative: about. 2016. Retrieved online from: https://www.pmi.gov/about.

31. Centers for Disease Control. Malaria. 2016. Retrieved online from: http://www.cdc.gov/malaria/.
32. Wang W, Qian H, Cao J. Stem cell therapy: a novel treatment option for cerebral malaria? Stem Cell Res Ther. 2015;6:141. doi:10.1186 /s13287-015-0138-6.

33. Shlomai A, Schwartz RE, Ramanan V, Bhatta A, de Jong YP, Bhatia SN, Rice CM. Modeling host interactions with hepatitis B virus using primary and induced pluripotent stem cell-derived hepatocellular systems. 2014.

34. Herrera-Carrillo E, Berkhout B. Bone marrow gene therapy for HIV/AIDS. 2015.

35. Li L, Krymskaya L, Wang J, Henley J, Rao A, Cao L, Tran C, Torres-Coronado M, Gardner A, Gonzalez N, Kim K, Liu P, Hofer U, Lopez E, Gregory P, Liu Q, Holmes M, Cannon P, Zaia J, DiGiusto D. Genomic editing of the HIV-1 coreceptor CCR5 in adult hematopoietic stem and progenitor cells using zinc finger nucleases. Mol Ther. 2013;21(6):1259-69. Academic Search Complete, EBSCOhost, viewed 28 April 2016.

36. Moreno J. How a Zika Virus Breakthrough vindicates stem cell research. Huffington Post. Published: March 15, 2016. Retrieved online from: http://www.huffingtonpost.com/jonathan-dmoreno/how-a-zika-virus-breakthr_b_9472846.html.

37. Mitchell JM, Conklin EA. Factors affecting receipt of expensive cancer treatments and mortality: evidence from stem cell transplantation for leukemia and lymphoma. Health Serv Res. 2015;50(1): 197-216 20p. doi:10.1111/1475-6773.12208.

38. Jaime-Perez JC, Heredia-Salazar AC, Cantu-Rodríguez OG, Gutierrez-Aguirre H, Villarreal-Villarreal CD, Mancias-Guerra C, Herrera-Garza JL, Gomez-Almaguer D. Cost structure and clinical outcome of a stem cell transplantation program in a developing country: the experience in Northeast Mexico. Oncologist. 2015;20(4):386-92 7p. doi:10.1634/theoncologist.2014-0218.

39. Chima SC, Mamdoo F. Ethical and regulatory issues surrounding umbilical cord blood banking in South Africa. South African J Bioeth Law. 2011;(2):79. 